\title{
The effect of forage species and stage of harvest on the processes of digestion occurring in the rumen of cattle
}

\author{
By D. E. BEEVER, M. S. DHANOA, H. R. LOSADA, R. T. EVANS, \\ S. B. CAMMELL AND J. FRANCE
}

The Animal and Grassland Research Institute, Hurley, Maidenhead, Berkshire SL6 5LR

(Received 5 December 1985-Accepted 21 April 1986)

1. Pure swards of perennial ryegrass (Lolium perenne L. cv. Melle) or white clover (Trifolium repens L. cv. Blanca) were harvested daily as either primary growth (May--June) or mid- (July) and late- (August-September) season 4-week regrowths and offered to Friesian steers at two levels of feed allowance (18 and $24 \mathrm{~g}$ dry matter (DM) $/ \mathrm{kg}$ live weight), to examine the effect of forage species and stage of harvest on nutrient digestion and supply.

2. The early- and mid-season grasses had low nitrogen $(23 \mathrm{~g} / \mathrm{kg} \mathrm{DM})$ and high water-soluble carbohydrate $(169 \mathrm{~g} / \mathrm{kg})$ contents whilst the late-season grass had a higher $\mathrm{N}$ content $(28 \mathrm{~g} / \mathrm{kg})$. All clover diets had high $\mathrm{N}$ (average $45 \mathrm{~g} / \mathrm{kg}$ ) and low water-soluble carbohydrate $(89 \mathrm{~g} / \mathrm{kg})$ contents, and DM digestibility on all diets ranged from 0.77 to 0.83 (mean of two feeding levels).

3. Mean total rumen volatile fatty acid concentrations were significantly $(P<0.001)$ higher on the clover diets, whilst on the grass diets molar proportions of propionate showed a slight but not significant decline with advancing season and tended to be higher than those on the clover diets. Mean rumen ammonia concentrations were significantly $(P<0.001)$ lower on the early- and mid-season grasses $\left(59 \mathrm{mg} \mathrm{NH}_{3}-\mathrm{N} / \mathrm{l}\right)$ than the late-season grass $(242 \mathrm{mg} / 1)$ and early-season clover $(283 \mathrm{mg} / \mathrm{l})$ which were all significantly $(P<0.01)$ lower than the midand late-season clovers $(372$ and $590 \mathrm{mg} / 1)$ respectively.

4. Rates of organic matter (OM) and $N$ digestion in the rumen were estimated using established nylon-bag techniques and found to be high on all diets, but significant effects due to forage species (clover $>$ grass; $P<0.001$ ) were detected, whilst overall potential degradability in the rumen exceeded 0.89 for both OM and $\mathrm{N}$ on all diets.

5. Significantly $(P<0.001)$ more $\mathrm{OM}$ entered the small intestine of calves fed on white clover $(10.2 \mathrm{~g} / \mathrm{kg}$ live weight) than those fed on ryegrass $(8.33 \mathrm{~g} / \mathrm{kg}$ ) and similar effects due to level of feeding $(\mathrm{g} / \mathrm{kg}$; low 7.9, high 10.6;

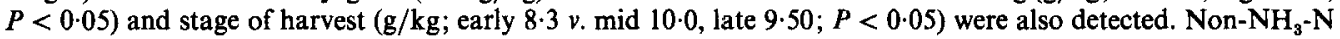
(NAN) flow $(\mathrm{g} / \mathrm{kg})$ to the small intestine was increased by forage species (grass 0.56 , clover $0.69 ; P<0.05$ ) and stage of harvest (early $0.59 v$. mid 0.65 , late $0.64 ; P>0.05$ ) whilst NAN flow $/ \mathrm{N}$ intake ranged from 0.96 to $1.65 \mathrm{~g} / \mathrm{g}$ (mean 1.25 ) on the grass diets and from 0.64 to $0.84 \mathrm{~g} / \mathrm{g}$ (mean 0.75 ) on the clovers $(P<0.001$ ).

6. Microbial $\mathrm{N}$ flow to the small intestine averaged 0.72 of duodenal NAN (grass 0.76 , clover 0.69 ). Efficiency of microbial $\mathrm{N}$ synthesis was high on all diets, $(\mathrm{g} / \mathrm{kg} \mathrm{OM}$ truly digested in the rumen; grass $33 \cdot 5$, clover $36 \cdot 3$ ), as was the estimated extent of in vivo feed $\mathrm{N}$ degradation ( $\mathrm{g} / \mathrm{g} \mathrm{N}$ intake; grass 0.75 , clover 0.79 ).

7. A model is described to simulate the progress curves of the ratio, degraded $\mathbf{N}$ :degraded $O M$ in the rumen for the six diets, using indices obtained in the present study. The results are ratified with the in vivo observations of $\mathrm{N}$ utilization in the rumen for the grass and clover diets.

8. It is concluded that both forage species and stage of harvest can significantly influence the processes of rumen digestion and nutrient supply, but with the fresh forages examined in the present study, it would appear that the processes of digestion in the rumen greatly outweighed the passage of potentially digestible nutrients from the rumen.

Previous studies with growing cattle consuming fresh forages indoors (Beever et al. 1985) and at pasture (Beever et al. 1986) have demonstrated extensive rumen proteolysis and substantial pre-duodenal losses of ingested nitrogen when forage $\mathrm{N}$ content exceeds $25-26 \mathrm{~g} / \mathrm{kg}$ dry matter (DM). These results confirm and extend earlier findings obtained with sheep (Beever et al. 1971, 1974, 1976, 1978; MacRae \& Ulyatt, 1974; Ulyatt \& Egan, 1979) but current knowledge on the causal mechanisms is limited. Equally, the earlier suggestion that legumes are less extensively degraded in the rumen due to an accelerated rate of passage out from the rumen remains equivocal, with recent experimentation giving inconsistent results.

The aim of the study reported in the present paper was to obtain information on the 
processes of rumen digestion occurring in cattle offered zero-grazed perennial ryegrass (Lolium perenne cv. Melle) or white clover (Trifolium repens $\mathrm{cv}$. Blanca) in order to permit a fuller interpretation of the forage and seasonal effects reported by Beever et al. (1986) and provide a more accurate assessment of the extent of total rumen digestion occurring on grass and legume diets. A brief report of the present work has been previously presented (Cammell et al. 1983).

\section{MATERIALS AND METHODS}

Forages

Two previously established pure swards of perennial ryegrass and white clover were managed with respect to fertilizer usage and harvesting procedures, as described earlier by Beever et al. (1985).

In total six crops were examined, comprising a primary growth and mid- and late-season regrowths of both forage species. All regrowths were approximately 4 weeks old at the time of feeding and the duration of the experiment was from early May to mid September.

\section{Animals and their management}

Twelve Friesian steers were standard-reared from birth until 4 months of age (approximately $120 \mathrm{~kg}$ live weight (LW)), when each was fitted with simple PVC cannulas into the dorsal sac of the reticulo-rumen and the proximal duodenum (Beever et al. 1978). Following recovery from surgery, all calves were kept in individual pens, and fed on lucerne (Medicago sativa) hay and barley concentrate until the commencement of experimental measurements, when they were transferred to the metabolism house.

The duration of each experimental period was approximately 6 weeks, consisting of a 3-week adaptation period, followed by a 3-week measurement period. Details regarding the harvesting and feeding of the diets were as described by Beever et al. (1985). Fresh water and mineral blocks were available at all times, the animal house environment was partially controlled with continuous lighting, and all animals receiving white clover were orally dosed twice daily at each feeding time with $5 \mathrm{ml}$ poloxalene $(980 \mathrm{ml} / 1$; Smith, Kline \& French) as a bloat preventative.

\section{Experimental design}

The study comprised six experimental periods corresponding to the six forages briefly described earlier. The animals were allocated at random to forages and two feeding levels (i.e. 18 or $24 \mathrm{~g}$ forage $\mathrm{DM} / \mathrm{kg} \mathrm{LW}$ ).

On day 1 of each measurement period, appropriate samples of duodenal digesta and duodenal microbes were obtained for ${ }^{15} \mathrm{~N}$ background determinations. On day 3, estimates of rumen fractional outflow rate of water and rumen volume were obtained for all calves, using single infusions of CrEDTA ( $300 \mathrm{ml} ; 3300 \mu \mathrm{g}$ chromium/1) at 09.00 hours immediately after feeding, followed by hourly sampling of rumen fluid, from 10.00 hours until the afternoon feed was given. Limited sampling between the two meals was adopted to avoid natural distortions in the decay curves which would be expected once the second meal is given. In interpreting the values, this reservation should be taken into account and some caution must be applied if the values are considered indicative of true mean daily values.

On days 5-11, total faecal and urine collections were undertaken, using previously described techniques (Thomson et al. 1981), whilst on days 8-10 during the balance trial, nylon bags $(45 \mu \mathrm{m}$, size $150 \times 60 \mathrm{~mm})$ containing the fresh forage $(5 \mathrm{~g} \mathrm{DM}$ equivalent) as offered to the animals on day 8 , were inserted into the rumen. To facilitate filling of the bags, the fresh forage was chopped in a bowl chopper (Lynhakker, Model 6H; G. Hansen, 
Copenhagen, Denmark) for $3 \mathrm{~min}$. After soaking in water for $10 \mathrm{~min}$, twelve bags were inserted into each animal at time zero (09.00 hours, day 8) and at the same time a further eight bags were prepared as controls by washing in cold water. Following removal from the rumen after exposure times varying between 3 and $48 \mathrm{~h}$, all bags were immediately placed in cold water and then washed thoroughly in cold water until the washing water was clear (approximately $20 \mathrm{~min}$ ).

On day 12, an intrarumen infusion of ruthenium phenanthroline (RuP) and CrEDTA was commenced in each calf, at a rate of $40 \mathrm{ml} / \mathrm{h}$, sufficient to supply $12 \mathrm{mg} \mathrm{Ru}$ and $120 \mathrm{mg}$ $\mathrm{Cr} / \mathrm{kg} \mathrm{DM}$ intake per $\mathrm{d}$. The intrarumen infusion was maintained until day 18 , when the infusate solution was prepared to contain $0.85 \mathrm{~g}^{15}\left(\mathrm{NH}_{4}\right)_{2} \mathrm{SO}_{4}(95 \%$ atom excess $) / \mathrm{kg} \mathrm{DM}$ intake per $\mathrm{d}$, in addition to the previously described levels of ruthenium and $\mathrm{Cr}$. This mixed infusion was maintained from days 18 to 21 inclusive and, over days 20 and 21 , continuous duodenal sampling was undertaken according to the procedures described by Evans $e t$ al. (1981). In addition, on day 21 , samples of rumen fluid were withdrawn at hourly intervals from each animal for a total of $24 \mathrm{~h}$.

\section{Sample processing}

Feeds. Representative samples of the harvested forage were taken daily and part was used to determine DM content by oven drying. A further portion was frozen, subsequently freeze-dried and ground, and retained for chemical analysis.

Forage residues from the nylon-bag studies were oven-dried overnight and then ground before chemical analysis.

Rumen fluid. All rumen fluid samples were immediately acidified with 5 M-sulphuric acid after removal from the rumen, centrifuged at $2500 \mathrm{rev} . / \mathrm{min}$ for $10 \mathrm{~min}$ and the resulting supernatant fractions were held frozen until required for analysis.

Duodenal digesta. All duodenal samples were processed according to previously described techniques (Beever et al. 1985) to provide ground, freeze-dried samples of whole and centrifuged digesta. In addition, microbial fractions were isolated from the whole digesta according to the procedures reported by Siddons et al. (1982). After separation, the microbial samples were freeze-dried, ground and stored, along with the digesta samples at $-15^{\circ}$, until required for analysis.

Faeces. Daily faecal outputs were accumulated by taking $10 \%$ of daily fresh weight voided. The resulting samples were thoroughly mixed and part was taken to estimate DM content by oven drying. A further sample $(1 \mathrm{~kg})$ was freeze-dried, ground and retained at $-15^{\circ}$ until required for analysis.

Urine. Daily urine outputs were accumulated by taking $1 \%$ of daily urine volume and a subsample of the bulked urine was held at $-15^{\circ}$ until required for analysis.

\section{Chemical analysis}

Contents of organic matter (OM), N, ammonia, cellulose, water-soluble carbohydrate, lignin, $\mathrm{Ru}, \mathrm{Cr}$ and volatile fatty acids (VFA) in appropriate samples and infusates were estimated by the procedures used by Beever et al. $(1985,1986) .{ }^{15} \mathrm{~N}$ enrichment of the duodenal digesta and microbial samples was estimated according to the technique described by Siddons et al. (1982), which comprised acid digestion followed by steam distillation. The distillates were dried on a heated block, taken up in a small quantity of water and ${ }^{15} \mathrm{~N}$ enrichment was estimated using a mass spectrometer (MS622; Micro Mass, Cheshire) with appropriate background corrections obtained by the analysis of digesta and microbial samples taken in each period before the infusion of ${ }^{15}\left(\mathrm{NH}_{4}\right)_{2} \mathrm{SO}_{4}$. 


\section{Calculation of results}

Flow rates of DM and specific nutrients to the small intestine were estimated according to the dual-phase marker technique proposéd by Faichney (1975).

The proportion of microbial $\mathrm{N}$ in duodenal digesta non- $\mathrm{NH}_{3}-\mathrm{N}$ (NAN) was estimated according to:

$$
\frac{{ }^{15} \mathrm{~N}: \mathrm{NAN}-\mathrm{N} \text { in duodenal digesta }}{{ }^{15} \mathrm{~N}: \mathrm{N} \text { in microbial fraction }}
$$

and an estimate of undegraded dietary $\mathrm{N}$ in duodenal NAN was obtained as the difference between total NAN flow less microbial $\mathrm{N}$ flow and endogenous $\mathrm{N}$ flow, the latter being assumed as $2 \mathrm{~g} \mathrm{~N} / \mathrm{kg} \mathrm{DM}$ intake (based on the work of Harrop (1974)).

\section{Statistical analysis}

The data were subjected to an analysis of variance using the statistical package GENSTAT (Alvey, 1977) which has a built-in facility for estimation of missing values, to compare the effect of forage species, season and level of feeding and their interactions. There were 8 and $16 \mathrm{df}$ for main plot and subplot variance respectively. Due to missing values, subplot error df were reduced to 13 (intake values), to 12 (digestion and flow values) and to 10 (microbial values).

All values, excluding the wash values (i.e. zero incubation time) from the nylon-bag study were analysed according to Ørskov \& McDonald (1979) and McDonald (1981) by fitting to the model:

$$
Y=a+b(1-\exp (-k t))
$$

where $Y$ is cumulative percentage degraded fraction $(\mathrm{OM}, \mathrm{N}), t$ is incubation time $(\mathrm{h})$, $k$ is rate of degradation; $a$ is the intercept on the $Y$ axis and $a+b$ is the assymptote with respect to $Y$ (potential degradability). The wash values were used to predict lag times from the fitted curves and these were not found to be significantly positive in any instance.

The estimated values for rates of degradation and potential degradability were then subjected to analysis of variance to compare treatments.

\section{RESULTS}

Chemical composition of the diet as offered to the animals is given in Table 1. All forages had OM contents between 878 and $922 \mathrm{~g} / \mathrm{kg}$ and the three grasses were characterized by higher water-soluble carbohydrate contents (mean $161 \mathrm{~g} / \mathrm{kg} \mathrm{DM}$ ) than the clovers $(89 \mathrm{~g} / \mathrm{kg}$ $\mathrm{DM})$, with a distinct seasonal effect being noted on the grass diets. Cellulose contents were very similar on the three grasses and the two regrowth clovers, and considerably lower than the value obtained for primary-growth clover. Lignin contents tended to be low on all diets, although the highest values were found on the clover diet. Early- and mid-season ryegrass contained on average $23 \mathrm{~g} \mathrm{~N} / \mathrm{kg}$ DM compared with $27 \mathrm{~g} \mathrm{~N} / \mathrm{kg}$ DM for late-season grass, all of which were considerably less than the values observed on the clover diets (mean $45.4 \mathrm{~g} / \mathrm{kg} \mathrm{DM}$ ).

During the experiment the calves gained between 65 and $81 \mathrm{~kg} \mathrm{LW}$, approximating to mean daily gains of $0.54 \mathrm{~kg}$ and $0.68 \mathrm{~kg}$ for grass and clover respectively. For all clover diets and the two regrowth grasses, the desired levels of feeding were achieved $(\mathrm{g} \mathrm{OM} / \mathrm{kg}$ $\mathrm{LW}$; low 15.9 , high 21.4 ) but on primary-growth mass, severe rejection problems were encountered and maximum intake was only $15.5 \mathrm{~g} \mathrm{OM} / \mathrm{kg} \mathrm{LW}$ irrespective of forage allowance. 
Table 1. Chemical composition ( $\mathrm{g} / \mathrm{kg}$ dry matter) of the diets as offered to the animals, their mean live weight $(\mathrm{kg})$ and the levels of organic matter $(O M)$ consumption $(\mathrm{g} / \mathrm{kg}$ live weight) achieved

\begin{tabular}{|c|c|c|c|c|c|c|}
\hline \multirow{2}{*}{$\begin{array}{l}\text { Forage... } \\
\text { Stage of growth... } \\
\text { Mean date of harvest... }\end{array}$} & \multicolumn{3}{|c|}{$\begin{array}{l}\text { Perennial ryegrass } \\
\text { (Lolium perenne) }\end{array}$} & \multicolumn{3}{|c|}{$\begin{array}{c}\text { White clover } \\
\text { (Trifolium repens) }\end{array}$} \\
\hline & $\begin{array}{l}\text { Early } \\
\text { May } 12\end{array}$ & $\underset{\text { July } 14}{\text { Mid }}$ & $\begin{array}{l}\text { Late } \\
\text { Aug. } 17\end{array}$ & $\begin{array}{c}\text { Early } \\
\text { June } 7\end{array}$ & $\begin{array}{c}\text { Mid } \\
\text { Aug. } 4\end{array}$ & $\begin{array}{l}\text { Late } \\
\text { Sept. } 10\end{array}$ \\
\hline OM & 893 & 922 & 903 & 903 & 878 & 897 \\
\hline $\begin{array}{l}\text { Water-soluble } \\
\text { carbohydrate }\end{array}$ & 179 & 158 & 145 & 93 & 82 & 93 \\
\hline Cellulose & 271 & 280 & 288 & 327 & 273 & 268 \\
\hline Lignin & 22 & 30 & 38 & 30 & 47 & 50 \\
\hline Total nitrogen & $22 \cdot 9$ & $22 \cdot 7$ & 27.5 & $46 \cdot 0$ & $43 \cdot 1$ & $47 \cdot 2$ \\
\hline \multicolumn{7}{|l|}{ Animal live wt*: } \\
\hline Low & 176 & 201 & 238 & 180 & 233 & 253 \\
\hline High & 177 & 200 & 245 & 179 & 239 & 268 \\
\hline \multicolumn{7}{|l|}{ OM intake*: } \\
\hline Low & 14.9 & $15 \cdot 3$ & 16.4 & $16 \cdot 4$ & $15 \cdot 4$ & $16 \cdot 2$ \\
\hline High & 15.5 & 21.7 & $21 \cdot 3$ & $21 \cdot 7$ & $20 \cdot 5$ & 21.6 \\
\hline
\end{tabular}

* Low and high relate to level of forage allowance, 18 and $24 \mathrm{~g}$ dry matter $/ \mathrm{kg}$ live wt per $\mathrm{d}$ respectively.

\section{Rumen digestion indices}

Mean rumen VFA concentrations ranged from 97 to $132 \mathrm{mM}$, with the animals fed on the clover diets having significantly $(P<0.001)$ higher values than those fed on ryegrass $(124$ v. $106 \mathrm{~mm}$ respectively). Small seasonal effects were apparent with respect to total VFA concentrations whilst acetate molar proportions for all diets showed little variation between 0.66 and 0.71 . Propionate levels on the grass diets showed some slight but non-significant seasonal effect and tended to be higher (mean 0.21 ) than those recorded for the clover diets $(0 \cdot 18)$, but a significant $(P<0 \cdot 05)$ difference was only detected between mid-season clover and the three grasses.

The most marked effects due to season and forage species were with respect to rumen $\mathrm{NH}_{3}-\mathrm{N}$ concentrations. Values on the early- and mid-season ryegrasses (mean $59 \mathrm{mg} / \mathrm{l}$ ) were significantly $(P<0.001)$ lower than the mean value observed on the late season grass $(242 \mathrm{mg} / \mathrm{l})$. In contrast, the mean values for the clover diets ranged from $283 \mathrm{mg} / 1$ (early clover) to $590 \mathrm{mg} / \mathrm{l}$ (late clover) with the two regrowth clovers being significantly $(P<0.01)$ higher than all other values. Differences due to level of feeding were inconsistent and not significant overall.

Fractional outflow rate $(/ d)$ of water from the rumen of grass-fed animals increased $(P<0.05)$ with respect to season $(2 \cdot 31,2 \cdot 99,3.64$ respectively) and feeding level (low 2.68 , high 3.02$)$. On the clover diets overall outflow rate $(/ \mathrm{d})$ was significantly $(P<0.05)$ higher on the mid-season $(3 \cdot 59)$ compared with the early-season clover $(2 \cdot 28)$, but this effect was not sustained with the late-season clover which was found to have a mean value identical $(2 \cdot 28)$ to that recorded for the primary growth. No consistent effects due to feeding level were detected on the clover diets. Estimates of rumen volume ranged between $14 \cdot 1$ and 38.6 litres equivalent to 0.27 to 0.63 litres $/ \mathrm{kg} \mathrm{LW}^{0.75}$, as illustrated in. Table 2 . Overall mean value for the grass-fed animals $\left(0.44\right.$ litres $\left./ \mathrm{kg} \mathrm{LW}^{0.75}\right)$ was significantly $(P<0.05)$ lower than the mean value obtained on the clover diets $\left(0.53\right.$ litres $\left./ \mathrm{kg} \mathrm{LW}^{0.75}\right)$ due largely to the values on mid-season grass being significantly $(P<0.001)$ lower than those for all other diets. Seasonal effects on the clover diets were not evident, whilst effects due to level of 


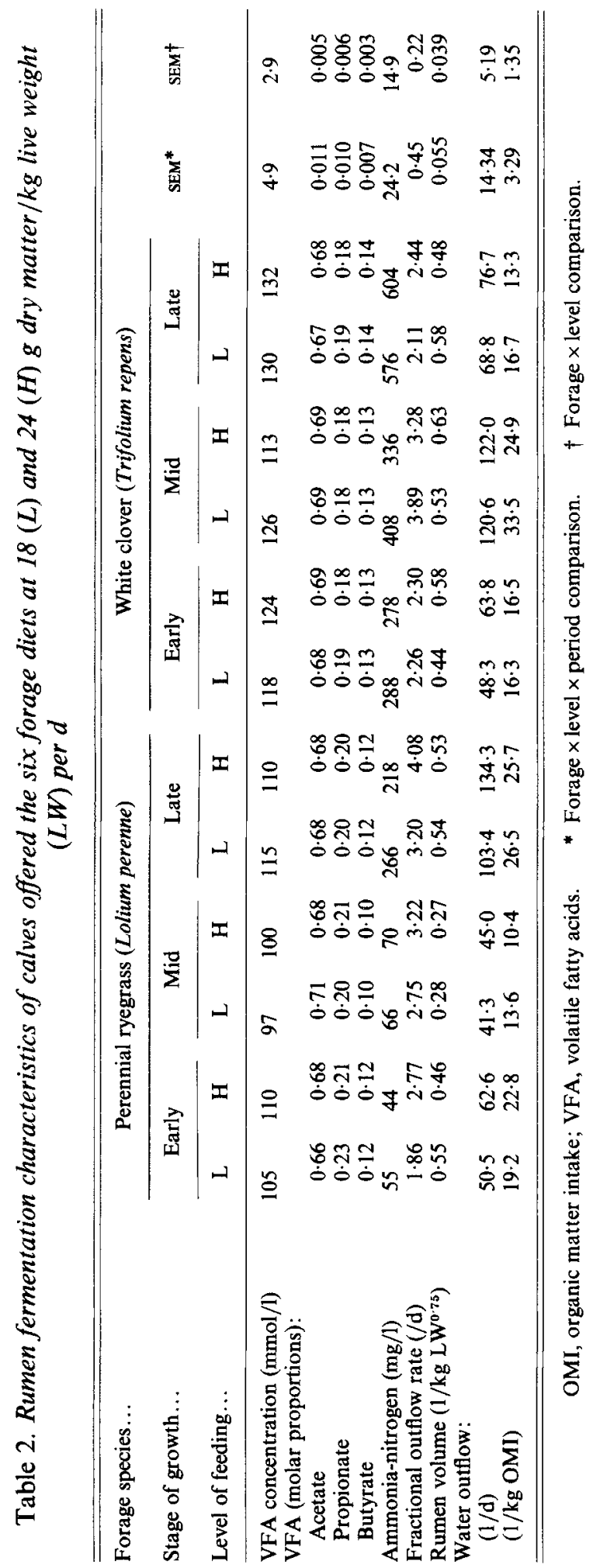


Table 3. Estimates of the rate of digestion and potential degradability of the six forages

(Values are means of forage allowance effects)

\begin{tabular}{|c|c|c|c|c|c|c|c|}
\hline \multirow{2}{*}{$\begin{array}{l}\text { Forage species... } \\
\text { Stage of growth... }\end{array}$} & \multicolumn{3}{|c|}{ Perennial ryegrass (Lolium perenne) } & \multicolumn{3}{|c|}{ White clover (Trifolium repens) } & \multirow[b]{2}{*}{ SEM } \\
\hline & Early & Mid & Late & Early & Mid & Late & \\
\hline \multicolumn{8}{|c|}{ Rate of degradation $(/ \mathrm{h})$ : } \\
\hline Organic matter & 0.072 & $0 \cdot 068$ & 0.072 & $0 \cdot 14$ & $0 \cdot 18$ & $0 \cdot 11$ & 0.0070 \\
\hline Nitrogen & 0.13 & $0 \cdot 14$ & 0.090 & $0 \cdot 16$ & 0.22 & 0.13 & 0.0060 \\
\hline \multicolumn{8}{|c|}{ Potential degradability $(\mathrm{g} / \mathrm{g})$ : } \\
\hline Organic matter & 0.913 & $0 \cdot 898$ & 0.904 & 0.903 & 0.895 & 0.913 & 0.0009 \\
\hline $\mathrm{N}$ & 0.929 & 0.893 & 0.953 & 0.936 & 0.939 & 0.940 & 0.0048 \\
\hline \multicolumn{8}{|c|}{ Instantly degradable fraction (wash value) $(\mathrm{g} / \mathrm{g})$ : } \\
\hline Organic matter & 0.157 & $0 \cdot 128$ & 0.073 & $0 \cdot 498$ & $0 \cdot 224$ & $0 \cdot 343$ & 0.0117 \\
\hline$N$ & $0 \cdot 117$ & $0 \cdot 064$ & $0 \cdot 173$ & $0 \cdot 508$ & $0 \cdot 147$ & 0.238 & 0.0121 \\
\hline
\end{tabular}

feeding on all diets were inconsistent (overall means $\left(1 / \mathrm{kg} \mathrm{LW}^{0 \cdot 75}\right)$, low $0 \cdot 48$, high $0 \cdot 49$ ).

Estimates of water outflow per $\mathrm{kg} \mathrm{OM}$ consumed are also presented in Table 2 and reflect the earlier results presented for rumen volume and fractional outflow rate. No significant overall differences were detected between the two forages $(1 / \mathrm{kg}$; grass $19 \cdot 7$, clover $20 \cdot 2)$ or the two levels of feeding $(1 / \mathrm{kg}$; low $21 \cdot 0$, high 18.9) but mean values recorded for late-season grass $(26.1$ litres $/ \mathrm{kg})$ and mid-season clover $(29.2$ litres $/ \mathrm{kg})$ were significantly $(P<0.001)$ higher than those for the other four forages examined.

\section{In vitro degradation studies}

Values illustrating the disappearance of forage $\mathrm{OM}$ and $\mathrm{N}$ from nylon bags inserted in the rumen are presented in Table 3.

On the grass diets, average rates of $\mathrm{OM}$ and $\mathrm{N}$ disappearance $(/ \mathrm{h})$ were 0.07 and 0.12 compared with mean values of $0 \cdot 14$ and 0.17 respectively for the clover diets (both $P<0.001$ ), and differences due to forage species were evident at all stages of harvest examined.

On all diets, the potential degradability of the $\mathrm{OM}$ and $\mathrm{N}$ fractions exceeded $0 \cdot 89$, but no significant $(P>0.05)$ effects due to stage of harvest were detected.

\section{In vivo digestion and nutrient supply to the small intestine}

Values presented in Table 4 refer to the quantities of $O M$ and $N$ consumed, entering the small intestine and digested in the whole tract of calves offered the six forages, in relation to animal LW.

OM digestibilities ranged from 0.76 to 0.84 but no significant differences with respect to forage species (grass 0.820 , clover 0.804 ) and level of feeding (low 0.820 , high 0.804 ) were established. With respect to season, a significant difference between the early-season and the mid- and late-season harvests was detected (early $0.832 v$. late 0.808 , mid 0.796 ; $P<0.001)$.

OM flow $(\mathrm{g} / \mathrm{kg} \mathrm{LW})$ to the small intestine varied between 6.7 and 13.8 and significant effects due to forage species (grass $8 \cdot 3$, clover $10 \cdot 2 ; P<0.01$ ), level of feeding (low 7.9, high 10.6; $P<0.001$ ) and season (mid 10.0, late 9.5 , early $8.3 ; P<0.05$ ) were detected. However, values for the amount of OM apparently digested in the rumen in relation to digestible OM intake appeared to be similar for all the grass diets $(0.64 \mathrm{~g} / \mathrm{g})$ and the early and late clover crops $(0.62 \mathrm{~g} / \mathrm{g})$. In contrast, the mid-season clover gave lower values and, due to this, significant effects with respect to season were detected (mid $0.56 v$. early 0.63 , late $0.62 ; P<0.05)$. 


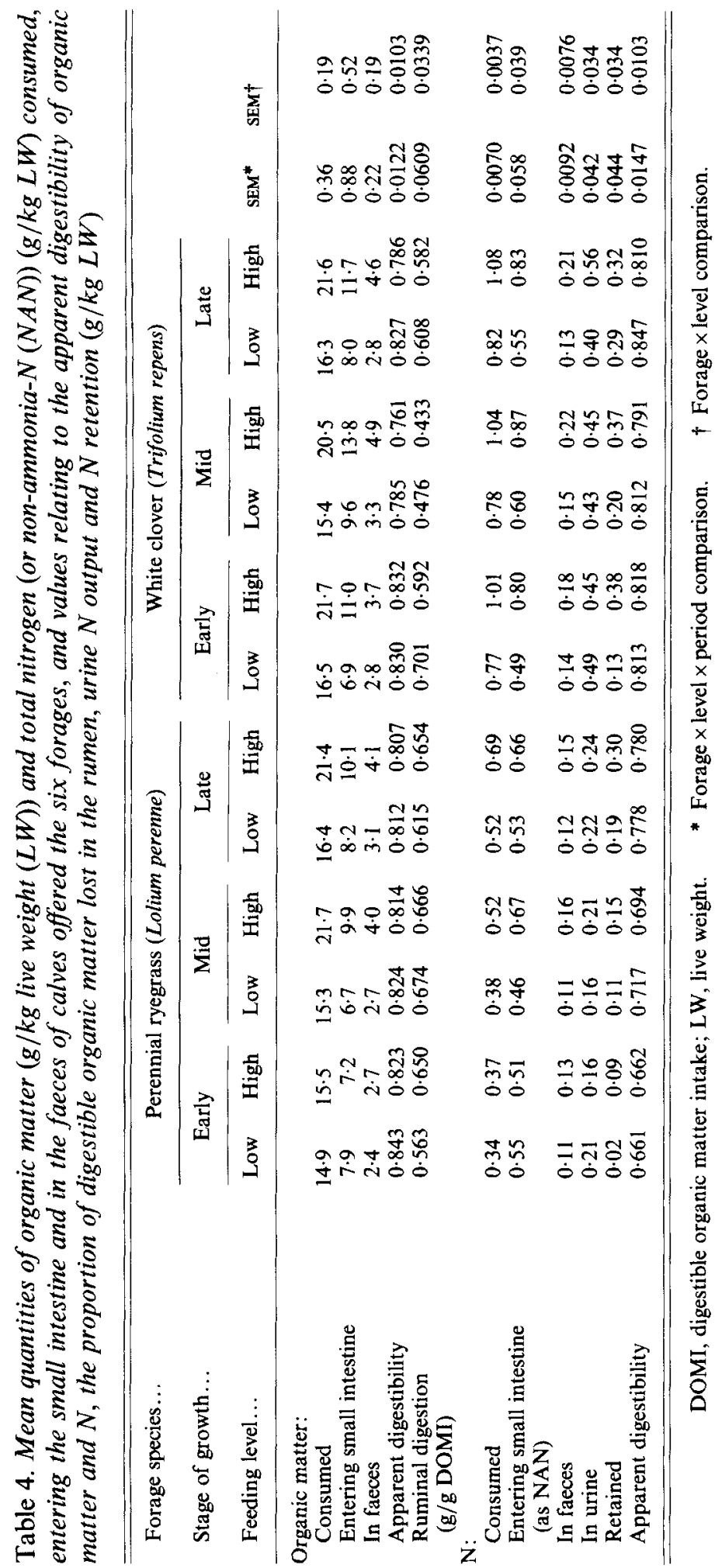


Daily $\mathrm{N}$ intakes ranged from 0.34 to $1.08 \mathrm{~g} / \mathrm{kg} \mathrm{LW}$ in response to the higher $\mathrm{N}$ contents of the late-season grass and the clover diets, whereas NAN flow showed a much narrower range from 0.46 to $0.87 \mathrm{~g} / \mathrm{kg} \mathrm{LW}$ per d. Significant effects due to forage species $(\mathrm{g} / \mathrm{kg} \mathrm{LW}$ per d; grass 0.56 , clover $0.69 ; P<0.05)$ and level of feeding $(\mathrm{g} / \mathrm{kg} \mathrm{LW}$ per d; low 0.53 , high $0.72 ; P<0.05)$ were noted whilst trends with respect to season were not significantly different $(\mathrm{g} / \mathrm{kg} \mathrm{LW}$; early 0.59 , mid 0.65 , late 0.64$)$. On the grass diets, NAN flow per unit $\mathrm{N}$ intake varied between 0.98 and $1.62 \mathrm{~g} / \mathrm{g}$ (average $1.25 \mathrm{~g} / \mathrm{g}$ ) compared with values on the clover diets which were all substantially below unity (mean $0.75 ; p<0.001$ ).

The apparent digestibility of $\mathrm{N}$ ranged from 0.77 to 0.85 on the late-season grass and the clover diets, in contrast to the early- and mid-season grasses $(0.66$ and 0.71 respectively) which were characterized by lower $\mathrm{N}$ intakes and, consequently, overall effects due to forage species (clover 0.815 , grass $0.715 ; P<0.001$ ) and season of harvest (late 0.804 , early 0.741 ; $P<0.001$ ), but not feeding level, were statistically significant.

Values are also presented in Table 4 for urinary $\mathrm{N}$ output, and whilst this was on average almost 2.5 times higher on the clover diets compared with the grass diets $(\mathrm{g} / \mathrm{kg} \mathrm{LW}$ per $\mathrm{d}$; clover 0.46 , grass 0.20$)$ a significantly $(P<0.01)$ higher $\mathrm{N}$ retention on the clover diets was observed ( $\mathrm{g} \mathrm{N} / \mathrm{kg} \mathrm{LW}$ per d; clover $0 \cdot 28$, grass $0 \cdot 14$ ). As expected, values were higher at the increased feeding level $(\mathrm{g} / \mathrm{kg} \mathrm{LW}$ per $\mathrm{d}$; low 0.16 , high $0.27 ; P<0.05)$ but despite an increase in LW during the experiment, a significant positive effect due to season was observed (g/kg LW per d; early $0.16 v$. mid $0.21 v$. late 0.28 ; all $P<0.05$ ).

Values in Table 5 indicate that the quantity of microbial $\mathrm{N}$ entering the small intestine accounted on average for 0.76 (grass) and 0.69 (clover) of duodenal NAN and only on the late clover, at the low level of feeding, was a value markedly less than 0.70 observed. Net yields $(\mathrm{g} / \mathrm{kg} \mathrm{LW}$ per d) were approximately $9 \%$ higher on the clover $(0.48)$ compared with the grass $(0.44)$ diets but significant differences were only observed with respect to feeding level (low 0.38 , high $0.54 ; P<0.01$ ). However, when expressed in relation to $\mathrm{N}$ intake, microbial $\mathrm{N}$ yields were significantly $(P<0.001)$ higher on the grass $(0.97 \mathrm{~g} / \mathrm{g})$ than on the clover $(0.51 \mathrm{~g} / \mathrm{g})$ diets.

Efficiencies of microbial $\mathrm{N}$ synthesis when expressed in relation to $\mathrm{OM}$ apparently digested in the rumen were high on all diets (more than $40 \mathrm{~g} / \mathrm{kg}$ ), this being particularly so with the mid-season clover. Alternatively, when expressed in relation to $O M$ truly digested in the rumen, by assuming that microbial biomass had an N:OM ratio of $0 \cdot 1$ (R. C. Siddons, personal communication), the values obtained showed a much narrower range, and the effect due to forage species was small $(\mathrm{g} / \mathrm{kg}$; grass $33 \cdot 5$, clover $36 \cdot 3)$ and not significantly different.

After assuming an arbitrary endogenous $\mathrm{N}$ in duodenal NAN equivalent to $2 \mathrm{~g} \mathrm{~N} / \mathrm{kg}$ DM intake, feed $\mathrm{N}$ degraded per unit $\mathrm{N}$ intake was calculated to vary from 0.64 to $0.87 \mathrm{~g} / \mathrm{g}$. Differences due to forage species were small (grass 0.747 , clover 0.786 ) and not significant, and seasonal effects $(\mathrm{g} / \mathrm{g}$; early 0.783 , mid 0.752 , late $0.765 ; P>0.05$ ) were also small.

Cellulose intake ranged from 4.5 to $7 \cdot 9 \mathrm{~g} / \mathrm{kg} \mathrm{LW}$ per d (grass $5 \cdot 4$, clover $6 \cdot 1$ ) and overall digestibility, whilst high on all diets $(>0.80)$, was marginally higher on the grass $(0.843)$ than on the clover $(0.824)$ diets $(P>0.05)$. A significant effect of overall digestibility due to season was observed (early 0.867 , mid 0.816 , late $0.818, P<0.001$ ), but no effect due to forage allowance was detected (low 0.837 , high $0.830 ; P>0.05$ ). On all diets, over 0.90 of digestible cellulose was fermented in the rumen and no seasonal or forage species and allowance effects were detectable. 


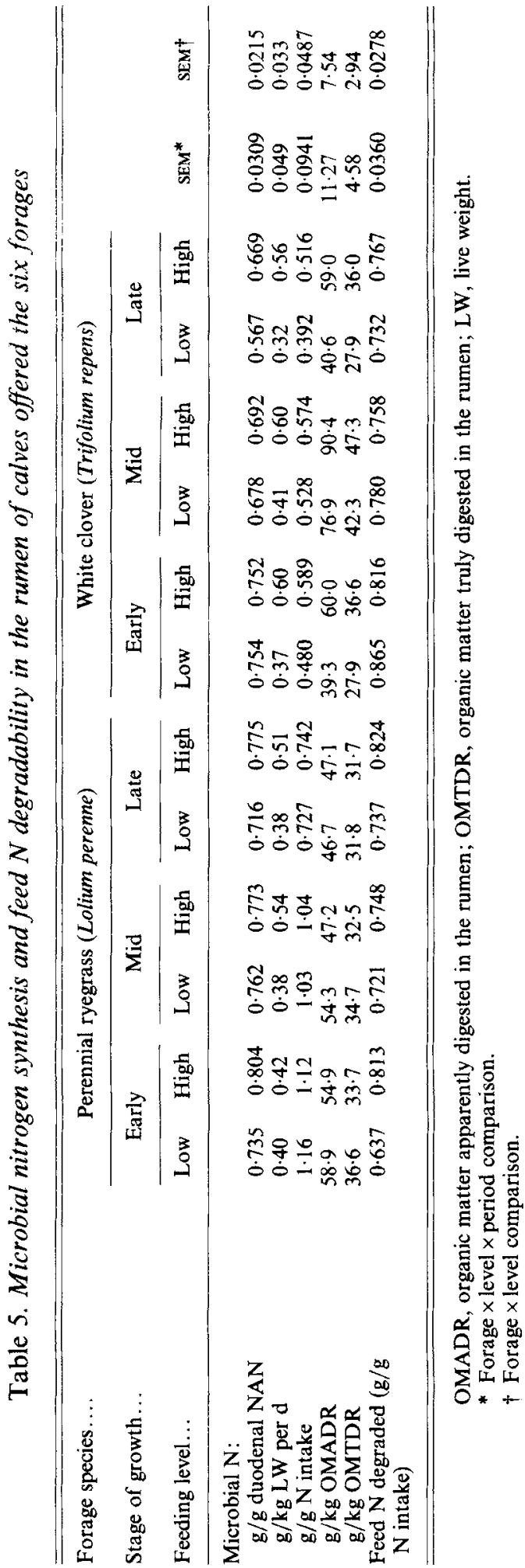




\section{DISCUSSION}

The forages used in the present study were similar to those examined in a grazing experiment by Beever et al. (1986) with respect to overall digestibility, $\mathrm{N}$ content and other major nutrients, but the intakes achieved in the previous study tended to be higher than those recorded in the present experiment. Nevertheless, the general outcome of the two studies with respect to rumen digestion and nutrient supply to the small intestine were in broad agreement. Excluding the mid-season clover used in the present study, the apparent extent of OM digestion in the rumen averaged 0.63 of digestible OM intake, compared with a mean estimate of 0.70 obtained in the grazing study, where estimates of OM intakes were considered to be less precise. In both studies no overall significant differences in the site of OM digestion due to forage species were detected, which agrees with the values of Ulyatt et al. (1980) for cattle grazing ryegrass or white clover, but not with Beever et al. (1985) who fed the same forages as used by Ulyatt et al. (1980) to stall-held cattle, and noted a significant depression in the extent of OM digestion in the rumen for the clover diets.

In the present study, mean daily NAN flows to the small intestine were 0.56 (grass) and 0.69 (clover) $\mathrm{g} / \mathrm{kg} \mathrm{LW}$, compared with mean values of 0.60 (grass) and 0.76 (clover) $\mathrm{g} / \mathrm{kg}$ LW recorded by Beever et al. (1986). Equally, both studies revealed high losses of $\mathrm{N}$ before the small intestine on all high- $\mathrm{N}$-containing diets (late-season grass and all clovers) and in each instance these were associated with elevated rumen $\mathrm{NH}_{3}$ concentrations. Beever et al. (1986) concluded that the rumen was the principal site of digestion for both ryegrass and white clover when offered in the fresh form, and their study was unable to detect any enhanced passage of undigested but potentially digestible material from the rumen. The values reported in the present study on the extent of cellulose digestion in the rumen clearly support this suggestion, whilst the estimates of the quantities of feed $\mathrm{N}$ escaping rumen degradation also add support to this conclusion.

On average 0.72 of duodenal NAN was of microbial origin and, over all diets, undegraded feed $\mathrm{N}$ was not more than 0.25 (grass) or 0.21 (clover) of $\mathrm{N}$ intake. From the yields of microbial $\mathrm{N}$, and assuming an $\mathrm{N}$ : OM ratio in microbial biomass of $0 \cdot 10$ (R. C. Siddons, personal communication), it can be calculated that the true rumen digestion of $\mathrm{OM}$ (disappearance plus microbial synthesis) accounted for 0.95 (grass) and 0.89 (clover) of the total quantity of OM digested in the whole tract. These values are marginally lower than the earlier ones suggested by Beever et al. (1986) ( 0.97 for both grass and clover), but still support the suggestion that if some potentially digestible $\mathrm{OM}$ escapes rumen fermentation on fresh forages, the quantitative significance of such is likely to be small, even on clover diets.

In a recent study, Moseley \& Jones (1984) examined the physical digestion of perennial ryegrass and white clover offered to sheep once daily at two levels of intake. They found that the rate of particle size reduction was greatest on all diets during the first $3 \mathrm{~h}$ post-feeding, but the overall rate of disappearance of large particles $(>1 \mathrm{~mm})$ was significantly faster on the clover compared with the grass diets. Associated with these changes in the large particle pools, they observed no significant increases in the size of the small particle pools on any of the diets and, from this, concluded that an increased rate of passage of small particles from the rumen must have occurred, especially on the clover diet. To support this hypothesis, Moseley \& Jones (1984) presented evidence based on microscopic examination of particles retained on a $1.18 \mathrm{~mm}$ sieve from rumen contents taken 6 and $18 \mathrm{~h}$ post-feeding either a grass or a clover diet. From the marked contrast in the physical nature of the particles arising from the two diets, they concluded that the particles of white clover were much more likely to pass freely from the rumen than those arising from the grass diet. In their study, however, no measures of either the fractional outflow rate or the digestion rate of particles were made. 
In the present study, forage digestion rates were measured and, whilst they were rapid on both diets, they were always highest on the clover diets. Equally, rumen-water fractional outflow rates, although only a partial indicator of the likely rates of passage of particles from the rumen, appeared to be uninfluenced by forage species, whilst in a recent study, Faichney (1986) reported that reduction in the particle size distribution of particles in the rumen reduced, rather that increased, the fractional outflow rates of these particles from the rumen. Furthermore, the results of the present study and those presented by Beever et al. (1986), which examined a wider range of fresh forages, indicated that the true digestion of $\mathrm{OM}$ in the rumen on both ryegrass and white clover was likely to be at least $0.9 \theta$ of total digestible $\mathrm{OM}$ intake.

Thus, whilst the results of the present study would not disagree with the observations relating to particle size reduction made by Moseley \& Jones (1984) and the relative distributions of the different particles with respect to time after feeding, they do not support the suggestion of a marked increase in the outflow of undigested small particles on the clover diets. Furthermore, whilst Moseley \& Jones (1984) subscribed the increased voluntary feed intake generally noted on clover compared with grass diets to an accelerated rate of passage of partially digested feed from the rumen, the present study would indicate that such increases in feed intake are likely to be related more closely to an increased rate of digestion, associated with an increased ease with which indigestible particles arising from white clover may leave the rumen compared with ryegrass. However, until specific measures of the rates of digestion and fractional outflow, along with the pool sizes of appropriate particles within the rumen are made in the same study, resolution of this issue will not be satisfactorily achieved.

On both forages the measured efficiencies of microbial $\mathrm{N}$ synthesis were higher than the mean value generally adopted by the Agricultural Research Council (1980) and, with the exception of mid-season clover, marked forage-induced or season-induced effects were not evident. However, in relation to the quantities of $\mathrm{N}$ consumed, the apparent efficiencies of captured $\mathrm{N}$ by the microbes were significantly higher on the grass diets, clearly a response to the lower levels of $\mathrm{N}$ supplied on the grasses. As mentioned earlier, the studies to measure the rates of $\mathrm{OM}$ and $\mathrm{N}$ digestion for the six forages revealed high values in all instances, and particularly so for the clover diets. However, in their present form, these values indicate nothing about the quantities of degraded $\mathrm{N}$ and $\mathrm{OM}$ which are available to the microbes, and how these may change with respect to time after feeding.

To examine this further, a simple dynamic model to predict changes in the ratio, degraded N:degraded OM supply with time following ingestion of the six diets was developed (see Appendix). Levels of feeding were arbitrarily fixed at $5 \mathrm{~kg}$ forage $\mathrm{DM} / \mathrm{d}$ given in two equal feeds at 09.00 hours and $8 \mathrm{~h}$ later. It was assumed that feeding rate $(\mathrm{g}$ eaten $/ \mathrm{h}$ ) was constant and all feed was consumed during the first $3 \mathrm{~h}$ post commencement of feeding. Compositions of the feeds were as given in Table 1, and the values for 'wash values', rate-constants and potential degradabilities were derived from solution of the model proposed by Ørskov \& MacDonald (1979) (Table 3). It was assumed that the "wash values' represented soluble material which would be totally available to the rumen micro-organisms immediately following ingestion and that 0.10 of potentially digestible nutrients (both $\mathrm{OM}$ and $\mathrm{N}$ ) would escape rumen fermentation during the first $3 \mathrm{~h}$ post-feeding, which is known to be associated with an increased rate of reticular and omasal contractions. No account was made within the model of microbial incorporation of degraded $\mathrm{N}$ and $\mathrm{OM}$.

The progress curves derived from this resolution are illustrated in Fig. 1 for the six diets. On the grass diets, degraded N:OM values tended to peak at between 35 and $42 \mathrm{~g} / \mathrm{kg}$ within approximately $3 \mathrm{~h}$ post commencement of feeding, and thereafter values declined to give values before the morning feed of between 14 and $22 \mathrm{~g} / \mathrm{kg}$. No persistent seasonal 


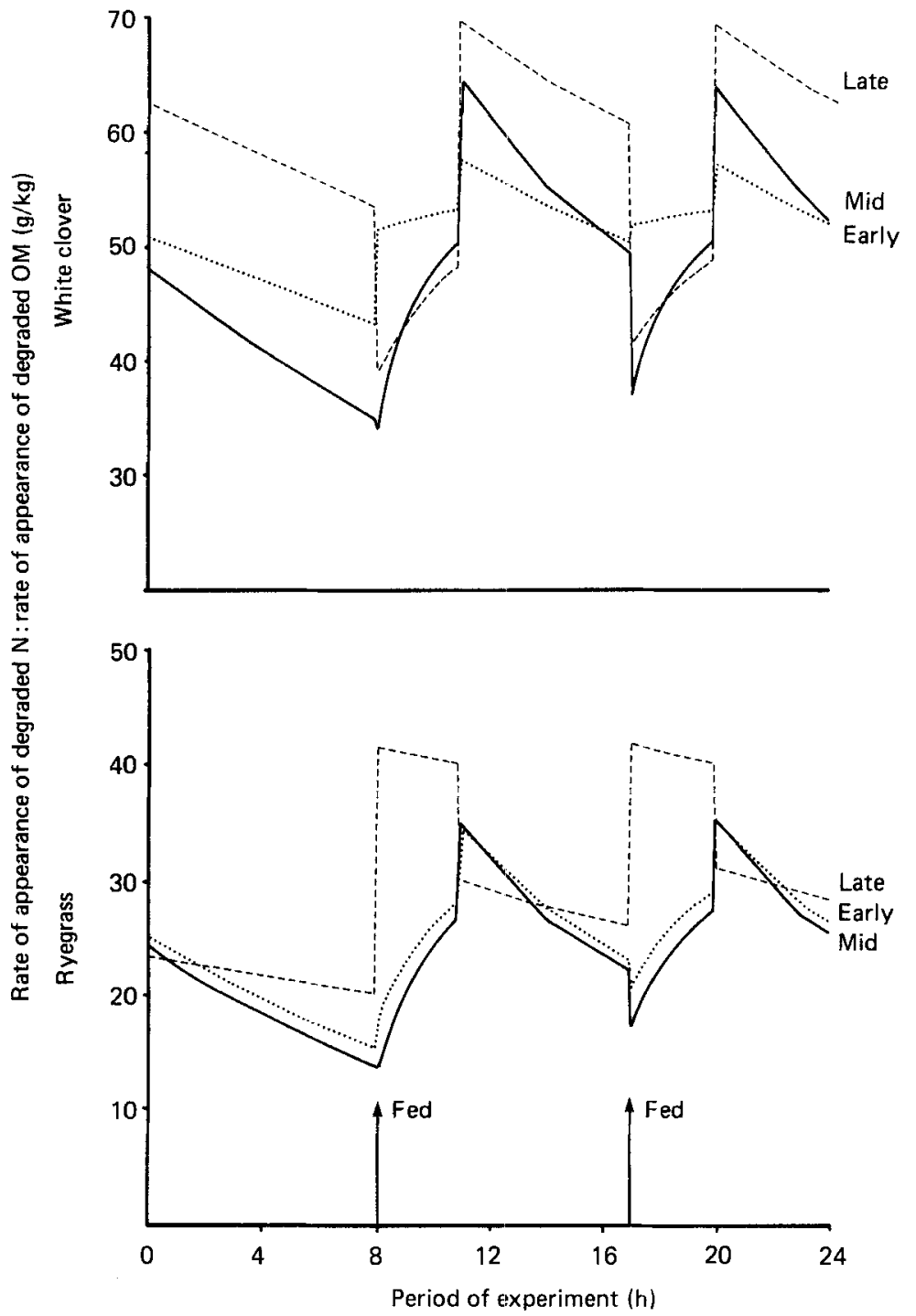

Fig. 1. The rate of appearance of degraded nitrogen: rate of appearance of degraded organic matter in the rumen following the ingestion of either perennial ryegrass (Lolium perenne) or white clover (Trifolium repens), harvested in early, mid- or late season.

effects were noted and generally the values derived were in broad agreement with the measured efficiencies of microbial $\mathrm{N}$ synthesis $(31$ to $37 \mathrm{~g} / \mathrm{kg} \mathrm{OM}$ truly digested in the rumen (OMTDR)) which appears to concur with the estimates of apparent synthesis of microbial $\mathrm{N}$ :dietary $\mathrm{N}$ of 1.14 and 1.04 for the early- and mid-season grasses respectively. It does not, however, identify a cause for the lower values noted on the late-season grass $(0 \cdot 73)$. This diet was characterized by a higher $\mathrm{N}$ content and a most pronounced rise in degraded N:OM ratio immediately post-feeding and the rumen $\mathrm{NH}_{3}$ levels noted on this diet were substantially higher than those recorded on the other two grasses. In contrast, the range in degraded N:OM values was much larger on the clover diets $(34-70 \mathrm{~g} / \mathrm{kg}$ ), indicating that degraded $\mathrm{N}: \mathrm{OM}$ supply exceeded the likely microbial requirement for much of the feeding cycle. Despite the higher $\mathrm{N}$ supply, microbial $\mathrm{N}$ synthesis/kg OMTDR ranged between 28 and $47 \mathrm{~g} / \mathrm{kg}$ on all diets and this imbalance between supply and 
utilization of degraded $\mathrm{N}: \mathrm{OM}$ was reflected in both the lower apparent efficiencies of microbial $\mathrm{N}$ synthesis:dietary $\mathrm{N}(0.39-0.59)$ and markedly higher rumen $\mathrm{NH}_{3}$ concentrations.

Mention has been made previously of the values for mid-season clover which did not appear to accord fully with the values derived for the other diets. Reasons for this difference, which can be broadly described as an elevated estimate of duodenal flow, are not immediately apparent. However, if the values relating to rumen water volume and fractional outflow rate are examined, an important difference (at least within the clover diets) can be identified. These values were obtained using a different technique to that employed to estimate duodenal flow and it can be seen that whilst all clover diets had similar rumen volumes $\left(0.44-0.63\right.$ litres $\left./ \mathrm{kg} \mathrm{LW}^{0.75}\right)$, water outflow from the rumen averaged 16.4 and 15.0 litres $/ \mathrm{kg} \mathrm{OM}$ intake on the early- and late-season clovers, compared with 29.3 litres $/ \mathrm{kg} \mathrm{OM}$ intake on the mid-season crop. If these enhanced flows, due to the higher fractional outflow are real, then despite being unable to offer an explanation for the occurrence of such, they do offer a possible reason why elevated flows of duodenal digesta were observed on the mid-season clover diets at both levels of feeding.

In summary, the results of the present study confirm previous suggestions that forage species can have a considerable effect on the processes of rumen fermentation, and provide considerable, albeit indirect, evidence to suggest that white clover, like ryegrass, when fed in the fresh form is extensively degraded in the rumen. Consequently, the suggestion of higher voluntary intakes on clover compared with ryegrass diets appears to be related more to an elevated rumen digestion rate than an increased rate of passage of digesta from the rumen, whilst the increased supply of NAN to the duodenum on clover diets appears to be due to an enhanced synthesis of microbial $\mathrm{N}$ in the rumen rather than an increased flow of undegraded $\mathrm{N}$ from the rumen.

The authors wish to thank Messrs A. R. Austin, R. J. Barnes, R. B. Marshall, D. L. Gale and Miss J. A. Bass for the technical assistance they gave to the present study. The Animal and Grassland Research Institute is financed through the Agricultural and Food Research Council, and part of this work was commissioned by the Ministry of Agriculture, Fisheries and Food.

\section{REFERENCES}

Agricultural Research Council (1980). Nutrient Requirements of Farm Livestock. Farnham Royal, Slough: Commonwealth Agricultural Bureaux.

Alvey, N. G. (1977). GENSTAT: A General Statistical Program. Harpenden, Herts: Rothamsted Experimental Station.

Beever, D. E., Cammell, S. B. \& Wallace, A. S. (1974). Proceedings of the Nutrition Society 33, 73A.

Beever, D. E., Kellaway, R. C., Thomson, D. J., MacRae, J. C., Evans, C. C. \& Wallace, A. S. (1978). Journal of Agricultural Science, Cambridge 90, 157-163.

Beever, D. E., Losada, H. R., Cammell, S. B., Evans, R. T. \& Haines, M. J. (1986). British Journal of Nutrition 56, 209-225.

Beever, D. E., Terry, R. A., Cammell, S. B. \& Wallace, A. S. (1978). Journal of Agricultural Science, Cambridge 90, $463-470$.

Beever, D. E., Thomson, D. J. \& Cammell, S. B. (1976). Journal of Agricultural Science, Cambridge 88, 61-70.

Beever, D. E., Thomson, D. J., Pfeffer, E. \& Armstrong, D. G. (1971) British Journal of Nutrition 26, $123-134$.

Beever, D. E., Thomson, D. J., Ulyatt, M. J., Cammell, S. B. \& Spooner, M. C. (1985). British Journal of Nutrition 54, 763-775.

Cammell, S. B., Beever, D. E., Thomson, D. J., Austin, A. R., Losada, H. R., Evans, R. T., Spooner, M. C. \& Terry, R. A. (1983). Animal Production 36, 501.

Evans, R. T., Skelton, K. V. \& Beever, D. E. (1981). Laboratory Practice 30, 997-1000.

Faichney, G. J. (1975). In Digestion and Metabolism in the Ruminant, pp. 277-291 [I. W. McDonald and A. C. I. Warner, editors]. Armidale, Australia: University of New England Publishing Unit.

Faichney, G. J. (1986). Proceedings of VI International Symposium on Ruminant Physiology, Banff (In the Press).

Harrop, C. J. F. (1974). Journal of Agricultural Science, Cambridge 83, 249-257. 
McDonald, I. (1981). Journal of Agricultural Science, Cambridge 96, 251-252.

MacRae, J. C. \& Ulyatt, M. J. (1974). New Zealand Journal of Agricultural Research 82, 309-319.

Moseley, G. \& Jones, J. R. (1984). British Journal of Nutrition 52, 381-390.

Orskov, E. R. \& McDonald, I. (1979). Journal of Agricultural Science, Cambridge 92, $499-503$.

Siddons, R. C., Beever, D. E. \& Nolan, J. V. (1982). British Journal of Nutrition 44, 377-89.

Thomson, D. J., Beever, D. E., Lonsdale, C. R., Haines, M. J., Cammell, S. B. \& Austin, A. R. (1981). British Journal of Nutrition 46, 193-207.

Ulyatt, M. J., Beever, D. E., Thomson, D. J., Evans, R. T. \& Haines, M. J. (1980). Proceedings of the Nutrition Society 39, 67A.

Ulyatt, M. J. \& Egan, A. R. (1979). Journal of Agricultural Science, Cambridge 92, 605-616.

\section{A P PENDIX}

\section{$A$ model of degraded $O M$ and $N$ appearance in the rumen}

Values obtained from the in situ digestion studies carried out in the present experiment (Table 3) and the feed compositional values (Table 1) were incorporated into a simulation of degraded $\mathrm{OM}$ and $\mathrm{N}$ appearance in the rumen for each of the six diets. The scheme assumed is shown in Fig. 2 and comprises two pools, one of potentially degradable material and the other of degraded material. Let $X_{1}$ denote the quantity (g) of potentially degradable material in the rumen at time $t(\mathrm{~h})$, and $X_{2}$ the quantity $(\mathrm{g})$ of degraded material. The $X_{1}$-pool has one influx (intake, $F_{01}(\mathrm{~g} / \mathrm{h})$ ) and two effluxes (passage, $F_{10}$ and digestion, $F_{12}$ ). The $X_{2}$-pool has two influxes (intake, $F_{02}$ and digestion of $X_{1}, F_{12}$ ) and two effluxes (passage and absorption, $F_{20}$ and microbial uptake, $F_{23}$ ). The model is therefore uniquely defined by the two first-order differential equations:

and

$$
\mathrm{d} X_{1} / \mathrm{d} t=F_{01}-F_{10}-F_{12}
$$

$$
\mathrm{d} X_{2} / \mathrm{d} t=F_{02}+F_{12}-F_{20}-F_{23}
$$

To determine the fluxes of interest and effect comparison between the six forages, a series of assumptions were made, with respect to level and frequency of feeding, duration of the meals and passage of potentially degradable material out of the rumen, and these have been included on p. 450 . Based on these assumptions, the intake and passage fluxes $F_{01}, F_{02}, F_{10}$ are calculated as follows for OM.

$$
\begin{array}{rlrl}
F_{01} & =f_{\mathrm{OM}} \Pi_{2, \mathrm{OM}} \times 2500 / 3, & & 24 M+8 \leqslant t<24 M+11, \\
& =0, \text { otherwise, } & & 24 M+17 \leqslant t<24 M+20, \\
& & \\
F_{10} & =0 \cdot 1 \times f_{\mathrm{OM}} \Pi_{2, \mathrm{OM}} \times 2500 / 3, & & 24 M+11 \leqslant t<24 M+14, \\
& 24 M+20 \leqslant t<24 M+23, \\
& =0, \text { otherwise, } & & \\
F_{02} & =f_{\mathrm{OM}} \Pi_{1, \mathrm{OM}} \times 2500 / 3, & & 24 M+8 \leqslant t<24 M+10, \\
& =0, \text { otherwise, } & & 24 M+17 \leqslant t<24 M+19,
\end{array}
$$

where $f_{\mathrm{OM}}$ is fractional OM composition of the ingested forage, $f_{\mathrm{OM}} \Pi_{1, \mathrm{OM}}$ and $f_{\mathrm{OM}} \Pi_{2}$, OM are its instantly-degraded and potentially degradable OM fractions respectively, and $M$ is the day number equal to the integer part of $t / 24$.

The digestion of potentially degradable material, $F_{12}$, is assumed to obey first-order kinetics. Therefore for OM

$$
F_{12}=k_{\mathrm{d}, \mathrm{OM}} X_{1, \mathrm{OM}}, \quad 24 M \leqslant t<24(M+1),
$$




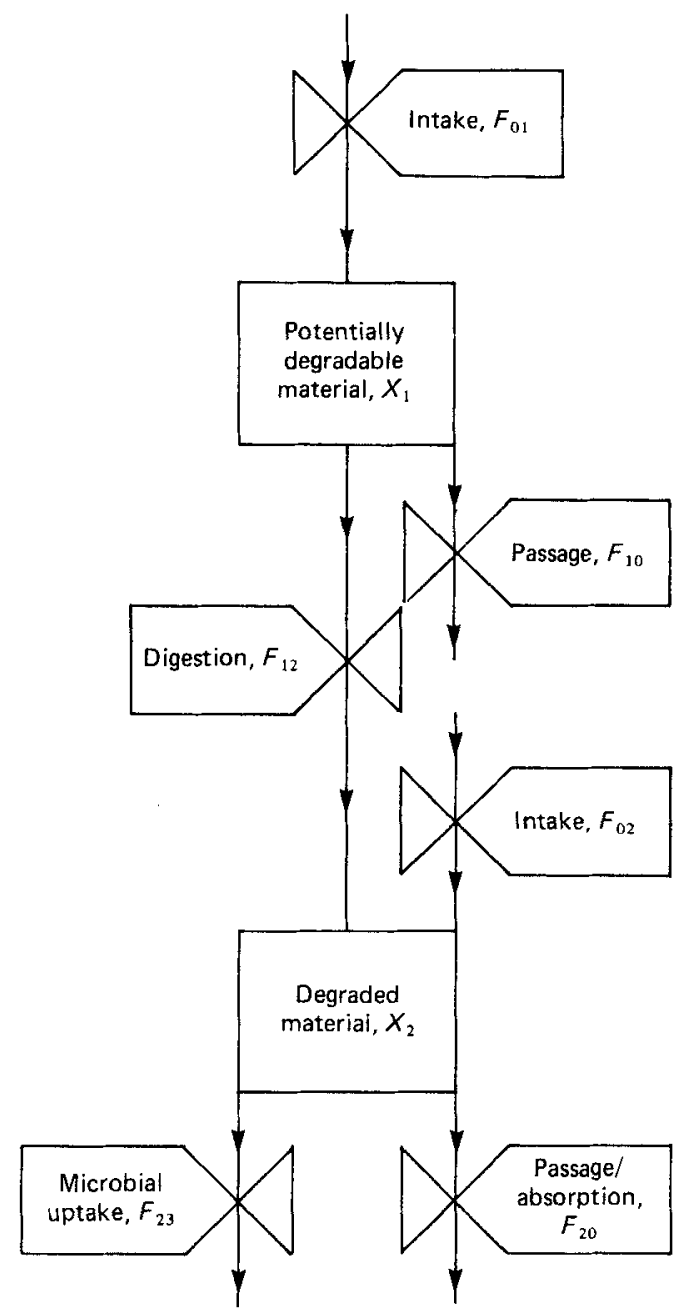

Fig. 2. A model of degraded organic matter and nitrogen appearance in the rumen. (The boxes denote pools and valve symbols denote fluxes.) For details, see Appendix.

where $k_{\mathrm{d}, \mathrm{om}}$ is the degradation rate $(/ \mathrm{h})$ and $X_{1, \mathrm{OM}}$ is the amount $(\mathrm{g})$ of potentially degradable $\mathrm{OM}$ in the rumen at time $t$. The unknown fluxes $F_{20}$ and $F_{23}$ are not needed to simulate the rate of rumen appearance of degraded material. The appearance rate of degraded OM can be simulated by integrating eqn ( $1 a)$ numerically using eqns $(2 a-d)$ and (3) and summing the fluxes $F_{02}$ and $F_{12}$ given by eqns $(2 e, f)$ and (3). To obtain the quasi-steady-state solution, the initial value of $X_{1}$ need not be known accurately.

Degraded $\mathrm{N}$ appearance is simulated in the same way as OM but for eqns $(2 a, c, e)$ and (3) being replaced by

$$
\begin{aligned}
F_{01} & =f_{\mathrm{N}} \Pi_{2, \mathrm{~N}} \times 2500 / 3, \\
F_{10} & =0 \cdot 1 \times f_{\mathrm{N}} \Pi_{2, \mathrm{~N}} \times 2500 / 3, \\
F_{02} & =f_{\mathrm{N}} \Pi_{1, \mathrm{~N}} \times 2500 / 3, \\
F_{12} & =k_{\mathrm{d}, \mathrm{N}} X_{1, \mathrm{~N}},
\end{aligned}
$$

where $f_{\mathrm{N}}, f_{\mathrm{N}} \Pi_{1, \mathrm{~N}}, f_{\mathrm{N}} \Pi_{2, \mathrm{~N}}, k_{\mathrm{d}, \mathrm{N}}, X_{1, \mathrm{~N}}$ are defined similarly to $f_{\mathrm{OM}}, f_{\mathrm{OM}} \Pi_{1, \mathrm{OM}}, f_{\mathrm{OM}} \Pi_{2, \mathrm{OM}}$, $k_{\mathrm{d}, \mathrm{OM}}, X_{1, \mathrm{OM}}$. 